\section{REFERENCES AND NOTES}

1. Brady, A. J.: Active state in cardiac muscle. Physiol. Rev., 48: 570 (1968).

2. Civan, M. M., and Podolsky, R. J.: Contraction kinetics of striated muscle fibers following quick changes in load. J. Physiol., 184: 511 (1966).

3. Friedman, W. F.: The intrinsic physiologic properties of the developing heart. Progr. Cardiovasc. Dis., 15: 87 (1972).

4. Hefner, L. L., and Bowen, T. E.: Elastic components of cat papillary muscle. Amer. J. Physiol., 212: 1221 (1967)

5. Huxley, A. F., and Simmons, R. M.: Mechanical properties of the cross-bridges of frog striated muscle. J. Physiol., 218: 59P (1971).

6. Huxley, A. F., and Simmons, R. M.: Proposed mechanism of force generation in striated muscle. Nature, 233: 533 (1971).

7. Lee, J. C., and Downing, S. E.: Left ventricular distensibility in newborn piglets, adult swine, young kittens, and adult cats. Amer. J. Physiol., 226: 1484 (1974).

8. McLaughlin, R. J., and Sonnenblick, E. H: Time behaviour of series elasticity in cardiac muscle: Real-time measurement by controlled-length techniques. Circ. Res., 34: 798 (1974).

9. McPherson, R. A., Lavelle, J. F., Friedman, W. F., and Covell, J. W. A technique for the automated analysis of cardiac muscle function. Comp. Biomed. Res., 5: 684 (1972)

10. Meiss, R. A., and Sonnenblick, E. H.: Controlled shortening in heart muscle. Velocity-force and active-state properties. Amer. J. Physiol., 222: 630 ([972).
11. Parmley, W. W, and Sonnenblick, E. H. Mechanical effects of increased series elasticity. Amer. J. Cardiol., 27: 376 (1971).

12. Parmley, W. F., and Sonnenblick, E. H.: Series elasticity in heart muscle: Its relation to contractile element velocity and proposed muscle models. Circ. Res., 20: 112 (1967)

13. Romero, T., Covell, J. W., and Friedman, W. F.: A comparison of pressurevolume relations of the fetal, newborn and adult heart. Amer. J. Physiol., 222: 1285 (1972).

14. Snedecor, G. W., and Cochran, W. G.: Statistical Methods (lowa State University Press, Ames, Iowa, 1967).

15. Truex, R. C., and Copenhaver, W. M.: Histology of the moderator band in man and other mammals with special reference to the conduction system. Amer. J. Anat., 80: 173 (1947)

16. Dr. J. W. Covell is recipient of National Heart and Lung Institute Career Development Award HE 21132

17. Dr. W. F. Friedman is recipient of National Heart and Lung Institute Career Development Award HE 41737

18. This research was supported by National Institutes of Health Program Project Grant HL 12373 and Graduate Training Grant HL 05846.

19. Requests for reprints should be addressed to: W. F. Friedman, M.D., Chief of Pediatric Cardiology, University Hospital, 225 W. Dickinson St., San Diego, Calif. 92103 (USA).

20. Accepted for publication January 28, 1976.

\title{
Bile Pigments in Humans and in Nonhuman Primates during the Perinatal Period: Composition of Meconium and Gallbladder Bile of Newborns and Adults
}

\author{
SHULA G. BLUMENTHAL, RICHARD M. IKEDA, AND BORIS H. RUEBNER ${ }^{26}$ \\ Department of Pathology, School of Medicine, University of California, and Primate Research Center, \\ Davis, California, USA
}

\section{Extract}

Meconium of human infants and rhesus monkey infants (Macaca mulatta) contained only about 0.10 of the amount of bilirubin in gallbladder bile of the same individuals.

Ninety-nine percent of the bilirubin in adult bile was conjugated. The proportion of conjugated bilirubin in infant bile and meconium was only slightly lower. Adult bile contained more bilirubin diconjugates than monoconjugates, whereas only $20 \%$ of the bilirubin in infant bile and meconium was in the form of diconjugates.

The predominant azopigment in adult bile was azopigment $\delta$ (a glucuronide). Infant bile contained less azopigment $\delta$, more azopig ment $\alpha$ (azodipyrrole), and a so far unidentified conjugated azopig ment (azopigment $\beta$ ). Azopigment $\beta$ was also found in meconium but adult gallbladder bile contained only trace amounts of this pigment.

\section{Speculation}

The metabolism of pigments in human meconium and bile is not yet well understood. To learn more about this area an animal model is required. In this investigation the pigments in adult human bile, infant bile, and meconium were compared with corresponding specimens from nonhuman primates. Our aim was to study the suitability of such an animal model for an investigation of this aspect of neonatal bilirubin metabolism.

The metabolism of bilirubin in adult primates and other animals is relatively well understood $(1,7)$, whereas that of newborns and fetuses is more controversial $(2,15,23)$. Hepatic glucuronyl transferase activity in fetal and newborn humans has been demonstrated $(13,15)$. However, it is not yet established whether the same transferase is responsible for the production of monoconjugates and diconjugates, nor is the specificity of glucuronyl transferase for substrates other than glucuronides established. Conjugation of exogenous and endogenous substrates in the fetus at term was found to be less efficient than in adults, and to increase soon after birth $(8,14,16,22)$. In the fetal dog hepatic conjugation of bilirubin and excretion into the intestine appeared to be the principal mechanism of bilirubin elimination (23). In fetal monkeys transfer of unconjugated bilirubin across the placenta predominated $(2,21)$. Conjugated bilirubin administered to monkey fetuses, however, was not transferred across the placenta in significant amounts (17). Even in primates, some bilirubin (ap- 
proximately $4 \%$ of the amount produced during gestation) was excreted into the bile and could be detected in the meconium (15).

Bilirubin in meconium (12) and in newborn infant feces (5) has been claimed to be mostly unconjugated. These results might be explained by the excretion of unconjugated bilirubin by the fetal and newborn liver but might also be the result of $\beta$-glucuronidase activity in the gallbladder or intestines which deconjugated bilirubin glucuronide produced by the liver (5).

Bilirubin or its derivatives may be reabsorbed from the meconium (20). This possibility increases the importance of identifying accurately the pigments in meconium. The recently developed chromatographic methods of Heirwegh et al. (10), which can distinguish between different conjugated bilirubins, represent a considerable advance in this field. We have therefore used these newer methods as well as older quantitative methods to compare the bilirubins in the gallbladder and meconium of newborn human infants and nonhuman primate infants with the pigments in the gallbladder of adult humans and adult nonhuman primates.

\section{MATERIALS AND METHODS}

\section{COLLECTION OF HUMAN AND MONKEY BILE AND MECONIUM}

Adult human bile was obtained from individuals over 25 years old autopsied within $24 \mathrm{hr}$ of death. The causes of death were heart attacks or strokes. Infant bile and meconium were obtained from full term stillborn infants and infants who lived for less than 2 days. Autopsies were performed no later than $24 \mathrm{hr}$ after death. All specimens were obtained from infants without obvious hepatic disease.

Adult monkey biles were obtained from monkeys aged 1-5 years. The animals were killed by an overdose of Diembutal and autopsied. Two animals had been exposed to a low level of ozone ( $0.8 \mathrm{ppm}$ for 7 days) before autopsy and the other three animals had been unexposed controls in that experiment. The infant monkeys used in this investigation had died shortly after birth without any obvious disease, most likely as the result of an accident or of mishandling by the mother. Autopsies were performed within $8 \mathrm{hr}$ of death. Meconium was obtained from mid- to lower parts of the small intestines.

The materials collected were immediately frozen in dark containers and kept at $-20^{\circ}$. Weighed aliquots of bile or meconium were thawed in the dark and diluted with $0.1 \mathrm{M} \mathrm{NaCl}$ solution. All meconium used was collected from the lower part of the small intestines.

\section{DETERMINATION OF CONJUGATED AND TOTAL BILIRUBIN (10)}

Total Bilirubin by Diazotized p-Iodoaniline. Biles and meconium from three individuals of each species were used for the determination of total bilirubin. In a glass-stoppered test tube 0.5 $\mathrm{ml}$ diluted test solution was mixed with $2.0 \mathrm{ml}$ accelerating reaction mixture (acetone-ethanol, $1: 1 \mathrm{v} / \mathrm{v}$ ) containing 2,6-di-tertbutyl-p-cresol at a concentration of $15 \mathrm{mg} / \mathrm{ml}$ and kept a few minutes on ice and in darkness. After mixing, $0.5 \mathrm{ml}$ diazo reagent was added and mixed. The diazo reagent was prepared as follows: $0.15 \mathrm{ml} \mathrm{NaNO} \mathrm{Na}_{2}(100 \mathrm{mg} / \mathrm{ml})$ was mixed with $4.0 \mathrm{ml} 2.0 \mathrm{M}$ $p$-toluene sulfonic acid. Two milliliters of this solution were mixed with $1.0 \mathrm{ml} p$-iodoaniline solution $(21 \mathrm{mg} p$-iodoaniline dissolved in $1.0 \mathrm{ml}$ glacial acetic acid). This mixture was allowed to stand for $3 \mathrm{~min}$ at room temperature. Then $5.0 \mathrm{ml}$ water were added, followed by $0.1 \mathrm{ml}$ ammonium sulfamate $(1.5 \mathrm{M})$. The solution was mixed and kept on ice for $5 \mathrm{~min}$.

After mixing, the diazo coupling process was allowed to proceed for $60 \mathrm{~min}$ on ice and in the dark. Excess diazonium salt was then destroyed by the addition of $3.0 \mathrm{ml}$ terminating reagent (ascorbic acid $10 \mathrm{mg} / \mathrm{ml}$ dissolved in $0.1 \mathrm{M} \mathrm{NaCl}$ ).

The azopigments were then extracted with $2.5 \mathrm{ml} n$-butyl acetate by vigorous shaking. Blanks were run in parallel, using a diazo blank reagent $(21 \mathrm{mg} p$-iodoaniline per $\mathrm{ml}$ glacial acetic acid) mixed with $2.0 \mathrm{ml} 2.0 \mathrm{M}$ p-toluene sulfonic acid and $5.0 \mathrm{ml}$ freshly prepared aqueous ascorbic acid solution $(100 \mathrm{mg} / \mathrm{ml})$.

The concentrations of total bilirubin were calculated from the absorption of diazotized $p$-iodoaniline pigments at $520 \mathrm{~nm}$. A calibration curve was obtained with a bilirubin solution prepared in $0.2 \mathrm{ml} 0.1 \mathrm{M} \mathrm{NaOH}$ (containing $1 \mathrm{mM}$ disodium EDTA), diluted with $5.0 \mathrm{ml}$ human serum, and later serially diluted with $0.15 \mathrm{M}$ $\mathrm{NaCl}(10)$. The serum used was from a normal adult individual. The readings of this calibration curve were within $5 \%$ of another curve in which saline was used for dilution. Readings were obtained at $520 \mathrm{~nm}$. Each point on the standard curve was the mean of four replicate experiments. All absorptions were read using a Beckman DR-Du-2 spectrophotometer no. 109810. With every subsequent experiment two known bilirubin concentrations were run as standards. Dry weights of bile and meconium were obtained by drying at $100^{\circ}$.

Unconjugated Bilirubin by Diazotized p-Iodoaniline (4). Bile and meconium from four different individuals of each species were used for the determination of unconjugated bilirubin. In a glassstoppered test tube $1.0 \mathrm{ml}$ diluted test solution was mixed with 1.0 $\mathrm{ml}$ salicylic acid buffer at $\mathrm{pH} 8.15$ (20 mg salicylic acid, 3.09 ascorbic acid, $2.7 \mathrm{~g} \mathrm{~K}_{2} \mathrm{HPO}_{4}$, and $9.5 \mathrm{ml} 2 \mathrm{M} \mathrm{KOH}$, adjusted to $50.0 \mathrm{ml}$ with distilled water) and $2.0 \mathrm{ml}$ chloroform (freshly washed with $10 \% \quad \mathrm{Na}_{2} \mathrm{~S}_{2} \mathrm{O}_{3}$ ). The mixture was shaken vigorously and centrifuged at $3,000 \mathrm{rpm}$ for $20 \mathrm{~min}$. The chloroform phase was separated from the aqueous solution and used for diazo coupling with $p$-iodoaniline.

One milliliter of the chloroform extract was mixed with $1.0 \mathrm{ml}$ ethanol and $1.0 \mathrm{ml}$ acetone. Then $0.5 \mathrm{ml}$ diazotized $p$-iodoaniline was added and diazo coupling was allowed to proceed as described above for total bilirubin determinations. After the addition of ascorbic acid the mixture was shaken and centrifuged. The azopigments present in the organic phase were separated and absorption was read at $520 \mathrm{~nm}$. One milliliter of a chloroform extract of adult bile known to contain no unconjugated bilirubin was used as a blank with the diazo reagent as described above.

A calibration curve was obtained as described above except that for this curve six different bilirubin concentrations in $1.0 \mathrm{ml}$ chloroform were employed.

The unconjugated azopigment fractions obtained were analyzed for the presence of contaminant conjugated azopigments by the thin layer chromatographic method described below.

Analysis of Bilirubin Conjugates in Bile and Meconium by Diazotized Ethyl Anthranilate Method. To prepare azopigment, $0.2 \mathrm{ml}$ appropriately diluted solution of bile or meconium in $\mathrm{NaCl}$ was transferred into a glass-stoppered test tube. To this $0.2 \mathrm{ml}$ glycine- $\mathrm{HCl}$ buffer at $\mathrm{pH} 2.7(0.4 \mathrm{M} \mathrm{HCl}$ adjusted to $\mathrm{pH} 2.7$ with solid glycine) was added. After mixing, $0.2 \mathrm{ml}$ diazoethyl anthranilate diazo reagent was added. The diazo reagent was prepared as follows: $0.1 \mathrm{ml}$ ethyl anthranilate was finely suspended in $10 \mathrm{ml}$ $0.15 \mathrm{M} \mathrm{HCl} ; 0.3 \mathrm{ml}$ sodium nitrite solution $(10 \mathrm{mg} / \mathrm{ml})$ was added, mixed, and allowed to stand at room temperature for $5 \mathrm{~min} ; 0.1 \mathrm{ml}$ ammonium sulfamate solution $(10 \mathrm{mg} / \mathrm{ml})$ was then added, mixed, and this diazo reagent was used 3 min later. This mixture of diazo reagent and appropriately prepared specimen was allowed to stand at room temperature for $30 \mathrm{~min}$, after which $0.2 \mathrm{ml}$ ascorbic acid solution $(10 \mathrm{mg} / \mathrm{ml})$ was added and mixed.

Azopigments were extracted by vigorous shaking with $0.5 \mathrm{ml}$ extraction solvent (pentan-2-one: $n$-butylacetate, 17:3, v/v). After centrifugation the organic phase was separated and used for thin layer chromatography.

\section{THIN LAYER CHROMATOGRAPHY}

Bile and meconium from four or five individuals of each species were used for chromatographic separation of azopigments obtained with assay procedures $\mathrm{B}$ and $\mathrm{C}$ using glass plates $(20 \times 20$ $\mathrm{crn}$ ) precoated with silica gel G (E. Merck Darmstadt, Germany).

The plates were developed successively with chloroformmethanol $(17: 3 \mathrm{v} / \mathrm{v}$ for $3.0-4.0 \mathrm{~cm}$, and then with chloroform containing $6 \%$ ethanol for $18.0 \mathrm{~cm}$ followed by chloroform- 
methanol-water $(65: 25: 3$ by volume) for $18.0 \mathrm{~cm}$. The plates were dried in a closed cabinet between developments. Development was allowed to proceed in the dark and at room temperature.

\section{ESTIMATION OF PROPORTIONS OF VARIOUS AZOPIGMENTS SEPARATED CHROMATOGRAPHICALLY}

The dried plates were photographed and then scanned with a Schoeffel S.D. 2000 rapid scan chromatograms analysis system. Scanning was performed using transmitted light. The illuminating wave length was $530 \mathrm{~nm}$ and the emission of spots was read at 530 $\mathrm{nm}$. The percentages of the azopigments in bile and meconium were calculated from the recorded charts.

\section{RESULTS}

\section{TOTAL BILIRUBIN (TABLE I)}

The highest bilirubin concentrations were found in human adult bile. Bile from adult monkeys, infant monkeys, and human infants contained approximately half as much bilirubin. Meconium contained less bilirubin than the bile of the same individuals. Approximately one-tenth of the concentration of bilirubin was present in meconium compared with the gallbladder bile.

\section{UNCONJUGATED BILIRUBIN (TABLE 2)}

Less than $1 \%$ of the bilirubin in adult bile, from both humans and monkeys, was unconjugated. When chloroform-extracted azopigments were chromatographically separated, all of the azopigment was azodipyrrole $\alpha$ o (9). This confirmed that the unconjugated fraction did not contain any bilirubin conjugates.

Infant human bile contained 1-5\% of unconjugated bilirubin and infant monkey bile 1-4\% unconjugated bilirubin, all in the azodipyrrole $\alpha$ o form.

Meconium of human infants and monkeys varied markedly in its percentages of unconjugated bilirubin. Some samples contained very little, others considerably more. When the chloroformextracted azopigments were chromatographically separated, most of the azopigment was azodipyrrole $\alpha$ o. However, small quantities of other azopigments, mainly other $\alpha$ 's and $\beta(9)$ were also present.

Table 1. Total bilirubin in meconium and bile (in milligrams per $g$ ) obtained from three human adults, three adult monkeys, three human infants, and three monkey infants

Fresh weight

\begin{tabular}{lcccc}
\cline { 2 - 5 } Source of material & Specimen 1 & Specimen 2 & Specimen 3 & Mean \\
\hline Human adult bile & 2.85 & 2.43 & 2.93 & 2.74 \\
Monkey adult bile & 1.68 & 1.71 & 1.36 & 1.58 \\
Human infant bile & 1.00 & 1.80 & 1.25 & 1.35 \\
Monkey infant bile & 1.96 & 1.83 & 1.09 & 1.53 \\
Human meconium & 0.17 & 0.23 & 0.20 & 0.20 \\
Monkey meconium & 0.18 & 0.07 & 0.13 & 0.16
\end{tabular}

Table 2. Percentage of unconjugated bilirubin in meconium and gallbladder bile from infant and adult humans and monkeys

\begin{tabular}{lc}
\hline Source of material & $\begin{array}{c}\text { \% Unconjugated } \\
\text { bilirubin }\end{array}$ \\
\hline Adult human bile & $<1.0$ \\
Adult monkey bile & $<1.0$ \\
Infant human bile & $1.0-5.0$ \\
Infant monkey bile & $1.0-4.0$ \\
Human meconium & $1.0-15.5$ \\
Monkey meconium & $1.0-11.1$ \\
\hline
\end{tabular}

CONJUGATED BILIRUBIN (TABLE 3 AND FIG. 1)

Adult Human and Monkey Bile. Bilirubin glucuronides predominated in the conjugated fraction of the autopsy bile samples. Thus, approximately $57 \%$ and $78 \%$ of azopigments were in the form of azopigment $\delta(8)$ (consisting mainly of $\beta$-D-monoglucuronoside) in adult human and monkey bile, respectively. Other conjugates were present in smaller amounts. Of the azopigments, $25 \%$ and $15 \%$ were in the form of azodipyrrole $\alpha o$ in adult human and monkey bile, respectively.

Infant Human and Monkey Bile. Bilirubin glucuronides were less predominant than in adults. Only $29.5 \%$ and $32.3 \%$ of the azopigments were in the form of azodipyrrole monoglucuronide (azopigment $\delta$ ) in infant human and monkey bile, respectively.

There was a higher proportion of azodipyrrole $\alpha 0 \quad(39.5 \%$ and $34.5 \%$ ) in infant human and monkey bile, respectively. An unknown conjugated azopigment $(\beta)$, found only in trace amounts in adults, accounted for $20.5 \%$ and $23.8 \%$ of the azopigments in the conjugated fraction of infant human and infant monkey bile, respectively.

Human and Monkey Meconium. The proportion of glucuronides in meconium was lower than in the gallbladder bile of the same individuals. Azodipyrrole monoglucuronide (azopigment $\delta$ ) accounted for $17.0 \%$ and $17.4 \%$ of the azopigments in human and monkey meconium, respectively. Of the azopigments, $40 \%$ and $29.8 \%$ were in the form of azopigment $\beta ; 32 \%$ and $40 \%$ were azodipyrrole $\alpha_{0}$ in human and monkey meconium, respectively.

\section{DISCUSSION}

Our observation that unconjugated bilirubin accounted for less than $1 \%$ of the total bilirubin in adult human and monkey autopsy bile (Table 2) agrees with previous observations on duodenal aspirates (9) from normal human adults. We found a lower percentage of the conjugated azopigment $\delta$ in gallbladder samples at autopsy (Table 3) than was found in duodenal aspirates of normal human adults (9). Bile collected immediately after death gave results similar to those collected some hours after death (3). Storage of specimens for 24 and $48 \mathrm{hr}$ at $4^{\circ}$ did not change significantly in their azopigment composition. Our human adult specimens thus had a higher percentage of azodipyrrole $\alpha$ o than those of Fevery et al. (9). This indicates a larger proportion of monoconjugates of bilirubin to diconjugates in our specimens (around 50\%) than in those of Fevery et al. (9). The monkey bile contained a higher percentage of azopigment $\delta(77.6 \%)$ and a lower percentage of azodipyrrole $\alpha 0(15 \%)$ than that of humans. This indicates a higher proportion of diglucuronides (about $70 \%$ ) in monkey bile than in human bile.

Newborn gallbladder bile also was mostly conjugated $(95-99 \%$, Table 2). This suggests that the liver of the newborn is capable of conjugating almost all the bilirubin excreted into the bile. The meconium contained no more than $15 \%$ of unconjugated bilirubin (Table 1). These findings do not support the results of Heringova et al. (12) and of Brodersen and Hermann (5). Both authors claimed that most of the bilirubin in the feces of newborns was in the unconjugated form. We are aware of the fact that substantial amounts of pigment in meconium are not readily extracted by any of the conventional methods. It seems likely that much of this unextracted pigment is not bilirubin. It is possible, however, that some unconjugated bilirubin was bound to proteins or other substances and therefore may not have appeared in our results.

The conjugated fraction of newborn bile contained a higher percentage of azodipyrrole $\alpha$ o, indicating a higher percentage of monoconjugates (Table 3 ), approximately $80 \%$ in infants $(70 \%$ in monkey infants) compared with approximately $50 \%$ in adult humans (30\% in adult monkeys). The higher percentage of monoconjugates in bile of newborns than of adults is consistent with the suggestion that the conjugation of bilirubin by the newborn liver is less efficient than that of the adult liver $(8,14,16$, 22, 23).

Newborn bile contained a lower proportion of glucuronide 
Table 3. Percentage of various azopigments in conjugated fraction of meconium and bile from infant and adult humans and monkeys

\begin{tabular}{|c|c|c|c|c|c|c|}
\hline \multirow[b]{2}{*}{ Source of material } & \multirow{2}{*}{$\begin{array}{c}\text { No. of } \\
\text { samples }\end{array}$} & \multicolumn{5}{|c|}{ Azopigment } \\
\hline & & $\delta$ & $\gamma$ & $\beta$ & $\alpha o$ & Other $\alpha$ 's \\
\hline Adult human bile & 5 & $57.3 \pm 3.7$ & $16.1 \pm 5.3$ & \pm Trace & $25.6 \pm 5.0$ & $3.0 \pm 2.4$ \\
\hline Adult monkey bile & 5 & $77.6 \pm 5.1$ & $6.3 \pm 2.4$ & \pm Trace & $15.0 \pm 5.2$ & $5.5 \pm 1.4$ \\
\hline Infant human bile & 4 & $29.5 \pm 3.3$ & $5.5 \pm 3.3$ & $20.5 \pm 5.5$ & $39.5 \pm 1.0$ & $5.0 \pm 2.5$ \\
\hline Infant monkey bile & 4 & $32.3 \pm 5.3$ & $7.3 \pm 3.3$ & $23.8 \pm 7.5$ & $34.5 \pm 6.7$ & $2.3 \pm 1.4$ \\
\hline Human meconium & 4 & $17.0 \pm 12.7$ & $2.0 \pm 1.6$ & $39.8 \pm 22.0$ & $32.0 \pm 11.2$ & $5.0 \pm 0.6$ \\
\hline Infant meconium & 4 & $17.4 \pm 2.1$ & $0-2$ & $29.8 \pm 3.4$ & $40.3 \pm 6.2$ & $8.2 \pm 4.1$ \\
\hline
\end{tabular}

lu1t

Adult

Baby

Baby

Human

Baby

Dog

bile

M. bile

H. bile

M. bile

meconium

meconium

bile

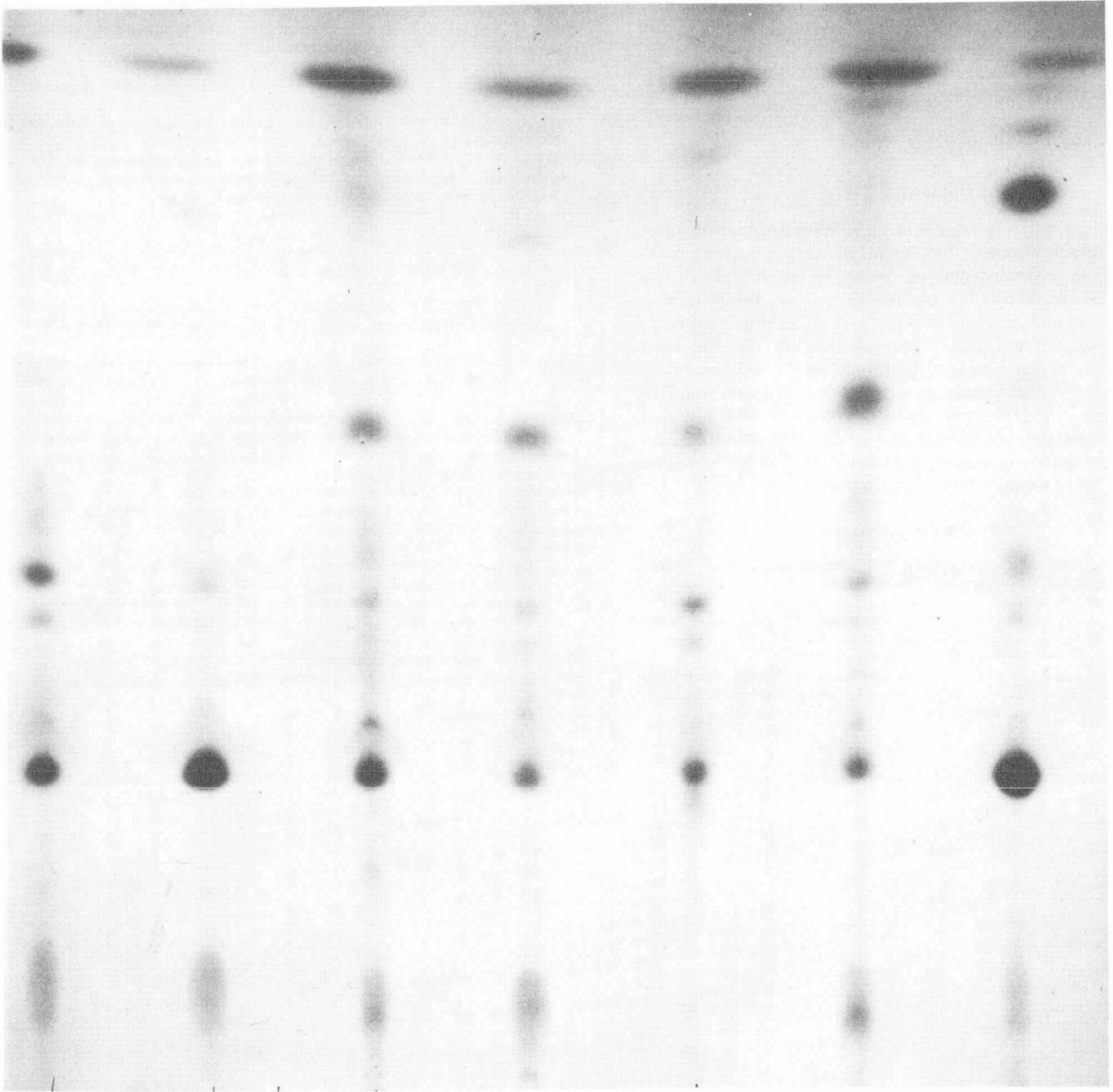

Fig. 1. Thin layer chromatographic separation of ethyl anthranilate azopigments in the conjugated fraction of meconium and bile obtained from infant humans $(H)$ and monkeys $(M)$ and adult humans and monkeys. For reference, dog bile was used in all chromatographic separations. $\alpha 0$ to $\delta$ are symbols for the azopigments according to the data of Heirwegh et al. $(9,10)$. A.L.*: application line. 
conjugates (pigment $\delta$ ) in relation to other conjugates (particularly pigment $\beta$ ) than that of adults (Table 3 ). Pigment $\beta$ is, so far, an unidentified conjugate not present in normal adult bile (see Fig. 1) This conjugate has, however, been observed in the biles from patients and Wistar rats with biliary obstruction (9). These observations indicate that in the conjugation of bilirubin the newborn liver uses a lower proportion of glucuronic acid and a higher proportion of other carbohydrates than the adult liver.

The proportion of monoconjugates in the conjugated bilirubin fraction of meconium, as indicated by the $\alpha 0$ fraction, was similar to that in infant bile, and amounted to approximately $75-80 \%$. Most of the monoconjugated bilirubin (approximately 60\%) was in the form of the unidentified conjugate which gave rise to azopigment $\beta$ (Table 3 ). Less than $20 \%$ was in the monoglucuronide form. The higher ratio in meconium of azopigment $\beta$ to monoglucuronide suggests that the bilirubin conjugates in meconium are not simply formed by the action of an intestinal $\beta$-glucuronidase (19) on bile and/or meconium. The possibility that the bile pigments in meconium were formed when the liver was less mature and produced a higher proportion of nonglucuronide conjugates arises. This suggestion also fits in with the observation that hepatic UDP-glucuronyl transferase is lower the more premature the infant is at birth (18). However, the higher proportion of unconjugated bilirubin in meconium than in newborn biles may be because of deconjugation of conjugated bilirubin by $\beta$-glucuronidase (18), mainly in the intestines of the fetus.

\section{SUMMARY}

Virtually all of the bile pigments in gallbladder bile of adult humans and rhesus monkeys $(M$. mulatta) were bilirubin conjugates. Less than $1 \%$ consisted of unconjugated bilirubin. The predominant conjugate was bilirubin diglucuronide. Infant human and monkey bile and meconium were also predominantly composed of conjugated bilirubins, only about $1-5 \%$ of the total bilirubin in bile and $1-15 \%$ in meconium being unconjugated. However, there was a difference in the type of conjugates found in infant bile when compared with those in adult bile. The bile and meconium of newborns contained less of the diglucuronide and more monoconjugates as well as a so far unidentified conjugate found only in trace amounts, if at all, in adults.

\section{REFERENCES AND NOTES}

1. Arias, I. M., Johnson, L., and Wolfson, S.: Biliary excretion of injected conjugated and non-conjugated bilirubin by normal and Gunn rats. Amer. J Physiol., 200: 1091 (1961).

2. Bernstein, R. E., Novy, M. J., Piasecki, G. J., Lester, R., and Jackson, B. T Bilirubin metabolism in the fetus. J. Clin. Invest., 48: 1678 (1969).

3. Blumenthal, S. G., and Ruebner, B. H.: Unpublished data.

4. Brodersen, R., Funding, L., Pedersen, A. O., and Röigaard-Petersen, H.: Binding of bilirubin to low-affinity sites of human serum albumin in vitro followed by co-crystallization. Scand. J. Clin. Invest., 29: 333 (1972).
5. Brodersen, R., and Hermann, L. S. Intestinal reabsorption of unconjugated bilirubin: A possible contributing factor in neonatal jaundice. Lancet, ii: 1242 (1963).

6. Brodersen, R., Jacobsen, J., and Hertz, H.: Bilirubin conjugation in the human fetus. Scand. J. Clin. Lab. Invest., 20: 41 (1967).

7. Callahan, E. W., and Schmid, R.: Excretion of unconjugated bilirubin in the bile of Gunn rats. Gastroenterology, 57: 134 (1969).

8. Dutton, G. J.: Glucuronide synthesis in foetal liver and other tissues. Biochem. J., 61: 141 (1959).

9. Fevery, J., Van Damme, B., Michiels, R., De Groote, J., and Heirwegh, K. P. M.: Bilirubin conjugates in bile of man and rat in the normal state and in liver disease. J. Clin. Invest., 51: 2482 (1972).

10. Heirwegh, K. P. M., Compernolle, F., Desmet, V., Fevery, J., Meuwissen, J. A. T. P., Van Roy, F. P., and De Groote, J.: Recent advances in separation and analysis of diazo-positive bile pigments. Methods Biochem. Anal., 22: 205 (1974)

11. Heirwegh, K. P. M., Van Hees, G. P., Leroy, P., Van Roy, E. P., and Jansen, F. $\mathrm{H}$ : Heterogeneity of bile pigment conjugates as revealed by chromatography of their ethyl anthranilate adopigments. Biochem. J., 120: 877 (1970).

12. Heringova, A., Jirsa, M., and Jirsova, V.: Chromatographic study of bile pigments in feces of newborns and infants. Biol. Neonat., 6: 277 (1964).

13. Jansen, F. H. Heirwegh, K. P. M., and Devriendt, A.: Foetal bilirubin conjugation. Lancet, $i: 702$ (1969).

14. Krasner, J., Juchau, M. R., and Yaffe, S. J.: Postnatal developmental changes in hepatic bilirubin UDP-glucuronyl transferase. Biol. Neonate, 23: 381 (1973).

15. Lampe, L., and Hafez, E. S.: Enterohepatic circulation of bilirubin in perinatal and postnatal life: An alternative pathway for control of neonatal hyperbilirubinemia. J. Reprod. Med., 11: 225 (1973)

16. Lathe, G. H., and Walker, M.: The synthesis of bilirubin glucuronide in animal and human liver. Biochem. J., 70: 705 (1958)

17. Lester, R., and Schmid, R.: Intestinal absorption of bile pigments. II. Bilirubin absorption in man. N. Engl. J. Med., 269: 178 (1963)

18. Ostrow, J. D: Photochemical and biochemical basis of the treatment of neonatal jaundice. In: H. Popper and F. Schaffner: Progress in Liver Diseases, Vol. IV, Chap. 26, pp. 447 (Grune and Stratton, New York, 1972).

19. Poland, R. L., and Odell, G. B.: Physiologic jaundice: The enterohepatic circulation of bilirubin. N. Engl. J. Med., 284: 1 (1971).

20. Ruebner, B. H., Kanayama, R., Bronson, R. T., and Blumenthal, S.: Meconium corpuscles in epithelium of fetal and newborn primates. Arch. Pathol., 98: 396 (1974).

21. Schenker, S., Bashore, R. A., and Smith, F. B.: Bilirubin disposition in foetal monkeys. In: I. A. D. Boucher and B. H. Billings: Bilirubin Metabolism, p. 199 (Philadelphia, 1969).

22. Strebel, L., and Odell, G. B.: Bilirubin uridine diphosphoglucuronyl transferase in rat liver microsomes: Genetic variation and maturation. Pediat. Res., 5: 548 (1971).

23. Thaler, M. M. Perinatal bilirubin metabolism. Advan. Pediat. 19: 215 (1972).

24. The protocol of this investigation was approved by the Committee on Research Involving Studies of Human Subjects at the University of California at Davis.

25. We would like to thank the Director and Staff of the California Primate Research Center of the University of California at Davis, and particularly Mr. L. Pulchritudoff, for their support throughout this investigation. We thank Drs. R. Schmid and A. MacDonagh, Gastroenterology Unit, Department of Medicine, San Francisco Medical Center, California and Dr. K. P. M. Heirwegh, Laboratory for Liver Physiopathology, Rega Institute, University of Leuven, Belgium, for their many helpful suggestions.

26. This work was supported by a National Institute of Child Health and Human Development Grant IR01 HD 07331-0I and Grant RR00169 to the University of California Primate Research Center.

27. Requests for reprints should be addressed to: B. H. Ruebner, M.D., Department of Pathology, School of Medicine, University of California, Davis, Calif. 95616 (USA).

28. Accepted for publication January 28, 1976 